\title{
Reuna
}

\section{CONEXÃO INTELIGENTE: A IMAGEM DO PARQUE ESTADUAL LAGOA DA JANSEN EM SÃO LUÍS (MARANHÃO) SOB A ÓTICA DE TURISTAS NO TRIPADVISOR}

\section{INTELLIGENT CONNECTION: THE IMAGE OF THE LAGOA DA JANSEN STATE PARK IN SÃO LUÍS (MARANHÃO) BY THE TOURISTS VIEW ON TRIPADVISOR}

http://dx.doi.org/10.21714/2179-8834/2019v24n2p89-107

\author{
Saulo Ribeiro dos Santos \\ Universidade Federal do Maranhão (UFMA), Brasil. \\ E-mail: saulosantosma@uol.com.br \\ José Manoel Gonçalves Gândara \\ Universidade Federal do Paraná (UFPR), Brasil. \\ E-mail: jmggandara@yahoo.com.br
}

Submissão: 12 Jul. 2017 Publicação: 15 Out. 2019. Sistema de avaliação: Double blind review. Centro Universitário UNA, Belo Horizonte - MG, Brasil. Editor geral: Prof. Dr. Gustavo Quiroga Souki

Este artigo encontra-se disponível nos seguintes endereços eletrônicos:

http://revistas.una.br/index.php/reuna/article/view/953

http://dx.doi.org/10.21714/2179-8834/2019v24n2p89-107

\section{Resumo}

A tecnologia tem favorecido a divulgação e promoção da imagem de um destino turístico, mediante sites específicos de turismo, como o TripAdvisor. Pois, neste é possível à inserção de comentários (positivos e negativos) acerca dos atrativos, empresas e serviços prestados no local visitado. Desta forma, objetiva-se no presente trabalho compreender a imagem percebida pelos turistas quanto a Lagoa da Jansen mediante análise de comentários no site TripAdvisor. A metodologia é considerada aplicada, descritivo-exploratório, de análise quantitativa. A amostra foi composta por quarenta e dois comentários dos turistas no site, quanto a "Lagoa da Jansen" na cidade de São Luís (Maranhão). A coleta de dados foi realizada nos meses de dezembro de 2015 a fevereiro de 2016. Analisou-se todos os comentários, utilizando o Excel para tabulação. Os principais resultados indicam que existe predominância de comentários negativos sobre a Lagoa da Jansen, mas que alguns positivos destacam aspectos quanto à paisagem e opção de lazer e entretenimento.

Palavras-chave: Tecnologia, Parque Estadual Lagoa da Jansen, Reputação Online, Mídias sociais, São Luís. 


\section{ABSTRACT}

Technology has favored the promotion of the image of a tourist destination, through specific tourism sites, such as TripAdvisor. For this is possible to insert comments (positive and negative) about the attractions, companies and services provided in the place visited. In this way, the aim of this work is to understand the image perceived by tourists about the Jansen Lagoon by analyzing comments on TripAdvisor. The methodology is considered applied, descriptive-exploratory, quantitative analysis. The sample was made up of forty-two comments from the tourists on the site, regarding the "Lagoa da Jansen" in the city of São Luís (Maranhão). Data collection was performed in the months of December 2015 to February 2016. All comments were analyzed using Excel for tabulation. The main results indicate that there is a predominance of negative comments about Jansen Lagoon, but that some positives highlight aspects of the landscape and leisure and entertainment options.

Keywords: Technology, Lagoa da Jansen State Park, Online Reputation, Social media, São Luís.

\section{Introdução}

Vive-se numa sociedade cada vez mais fervorosa pelo consumo, e a atividade turística aparece como uma alternativa na comercialização de produtos, serviços, imagens, recursos e valores simbólicos (GÂNDARA, 2008) que miram a satisfação das necessidades do homem, com o objetivo de atender anseios e expectativas dos turistas (PINTO, 2012).

Além disso, o turismo alia-se a tecnologia (BUHALIS, 2000) com o objetivo de captar novos visitantes e investidores que possam promover o desenvolvimento do lugar, inovando, requalificando e promovendo singularidades da identidade local. A evolução do destino turístico quanto à imagem (MARUJO, 2008) promovida pelos ganhos tecnológicos, criam diferenciais como a inclusão de produtos turísticos ou até mesmo uma nova forma de aproveitamento do atrativo, garantindo vantagem competitiva, o que pode tornar determinante na escolha do mesmo (BLANCO, 2015).

A imagem do destino (STEIKE; REIS JUNIOR; COSTA, 2014) forma-se pela captação e armazenagem dos locais visitados pelo turista (Gândara, 2008), portanto, a mesma deve chamar atenção pela qualidade dos atrativos, e, a tecnologia tem favorecido este aspecto quanto à avaliação, pois, os visitantes têm realizado comentários em diversas mídias sociais, e sites direcionados ao turismo, como o Tripadvisor, em que é possível a realização de comentários tanto nos aspectos positivos e negativos, relacionados aos pontos turísticos, serviços, empreendimentos, entre outros (LAW; QI; BUHALIS, 2010; LIU, 2000; MONTARDO, 2009; TRIPADVISOR, 2013).

O conteúdo gerado nas avaliações de desempenho pelos usuários na internet tem contribuído para uma nova visão quanto ao destino ou produto turístico (GÂNDARA; FRAIZ; MANOSSO, 2013). Pois, com o avanço tecnológico, o usuário tem criado uma rede de avaliação que permite o aumento do fluxo de informações sobre determinado serviço ou produto, facilitando a comunicação e análise (REINO et al., 2012). 
Além disso, o comportamento do consumidor modifica-se com a tecnologia (BAGGIO; DEL CHIAPPA, 2014; BUHALIS, 2000) facilitando a interação entre diversos usuários e fornecedores. Portanto, compreender a visão e experiência do turista através dos sites de opinião, caracteriza-se como uma forte opção de entender o que pode ser aperfeiçoado, melhorado e modificado (SOLOMON, 2011).

A capital do estado do Maranhão, São Luís, diferencia-se quanto aos demais destinos turísticos brasileiros, pois, o seu produto turístico não está concentrado somente no segmento cultural, mas também no de natureza, com espaços na urbe, como o caso de parques urbanos que são utilizados como local para visitação (SANTOS et al., 2013). Em meados de 2001, São Luís presenciou a urbanização do entorno da Unidade de Conservação Estadual Parque Ecológico da Lagoa da Jansen que promoveu benfeitorias ao local, criando ambientes de lazer e entretenimento para a população e visitantes (COELHO, 2002).

Mediante tal justificativa, questiona-se: que imagem os turistas possuem sobre o parque estadual Lagoa da Jansen em São Luís enquanto produto turístico? Neste segmento, surge este trabalho de investigação, com o objetivo de compreender a imagem percebida pelos turistas quanto a Lagoa da Jansen mediante análise dos comentários no site Tripadvisor. Para alcance do objetivo, utilizou-se dos seguintes procedimentos metodológicos: levantamento do estado da arte sobre imagem, percepção e tecnologia; caracterização sobre Parque Estadual Lagoa da Jansen; análise da reputação online com base nos comentários no site Tripadvisor ao longo do ano de 2015. O tratamento dos dados foi apresentado por meio de tabelas, gráficos e quadros, apontando principalmente os resultados alcançados, utilizando linguagem apropriada para uma compreensão adequada sobre a temática apresentada.

O artigo está dividido em metodologia, onde aborda-se as questões sobre os métodos e técnicas utilizados. Em seguida, faz-se uma descrição do parque urbano Lagoa da Jansen. Após, analisa-se os comentários dos usuários do site Tripadvisor, e por fim são apresentadas as considerações finais.

\section{Procedimentos metodológicos}

Quanto aos objetivos, a pesquisa caracteriza-se como descritiva e exploratória, sendo que a descritiva tem por fim criar meios para descobrir e observar fenômenos, de forma a classificá-los, descrevê-los e interpretá-los para então estabelecer relações entre as variáveis de estudo. Quanto ao aspecto exploratório, no sentido de levantar dados que servirão de apoio para futuras pesquisas (CERVO; BERVIAN, 2004).

Classifica-se como bibliográfica, pois, "procura explicar um problema a partir de referências teóricas publicadas em documentos" (CERVO; BERVIAN, 2004, p. 55). Além disso, buscou-se como fonte as bases de dados - Redalyc, CAPES e Publicações em Turismo -, utilizando palavras chaves como: imagem turística, parques urbanos e reputação online.

Classifica-se também como documental, que refere-se à análise de materiais que ainda não receberam um tratamento analítico e que podem ser reelaborados, como esclarece Creswell (2007, p. 192): "documento públicos, como atas e reuniões e jornais; documentos privados, como registros, diários e cartas e discussões via email". 
Quanto aos fins, teve abordagem qualitativa utilizando a coleta de dados via comentários dos usuários do site Tripadvisor. Pois, a reputação online tem como objetivo compreender a conversação de usuários em espaços administrados por uma empresa que dão voz ao consumidor (MONTARDO, 2009).

A reputação online é também uma questão de monitoramento de mídias sociais, e tem crescido nos últimos anos o interesse em acompanhar tais ferramentas como forma de estudo, para compreender as métricas válidas (CERQUEIRA; SILVA, 2011).

Como a pesquisa trata da imagem, Barich e Kotler (1991) e Mason (1993) acreditam que a reputação concebe uma dimensão da imagem. Já para Chun (2005), a imagem é parte integrada da reputação, correspondendo à percepção e perspectiva dos stakeholders internos e externos.

Gândara, Fraiz Brea e Manosso (2013) pesquisaram a experiência dos hóspedes em hotéis termais na Espanha e afirmam que é importante a pesquisa em sites de depoimentos online para compreender e analisar as informações e dados postados na mídia social com o objetivo de melhorar os serviços.

A amostra da pesquisa é não-probabilística, pois, os critérios utilizados são baseados em julgamentos pessoais e representam uma população (GIL, 2006). Como base para coleta de dados (comentários), utilizou-se o site Tripadvisor que já foi utilizado por Beal e Strauss (2008) e María-Dolores, García e Mellinas (2012) para análise de reputação online.

O conjunto de opiniões que se realiza na internet sobre uma determinada marca, bem ou serviço, é o que constitui a 'reputação online' de uma empresa. A princípio, trata-se de algo que está fora do alcance do empresário, já que se supõe que todas as opiniões são emitidas por usuários independentes [...] é importante compreender também em que medida os internautas recorrem às opiniões de outros usuários para tomar uma decisão de compra ${ }^{1}$ (MARÍA-DOLORES; GARCÍA; MELLINA, 2012, p. 3) (tradução nossa).

Do início dos comentários até o dia 25 de janeiro de 2016 existiam 900 comentários sobre a Lagoa da Jansen em São Luís (TRIPADVISOR, 2016), sendo que foram analisados para este trabalho 42 comentários postados no período compreendido entre dezembro de 2015 a fevereiro de 2016 (caracterizado como alta estação no turismo de São Luís).

Os comentários foram lidos e realizou-se uma categorização dos mesmos numa planilha do Excel. Dividiu-se em sete parâmetros conforme Quiroga, Mondo e Castro Júnior (2014), sendo: local de origem (cidade ou país do usuário), título do

1 El conjunto de opiniones que se realizan em Internet, sobre una marca, bien o servicio, es lo que constituye la 'reputación online' de una empresa. Em principio, se trata de algo que queda fuera del alcance del empresario, ya que se supone que todas essas opiniones son vertidas por usuarios independientes.[...] También resulta interesante saber, en qué medida los internautas recurren a las opiniones de otros usuários para tomar una decisión de compra. 
comentário (título que o usuário utilizou), comentário (comentário do usuário), data (dia, mês e ano dos comentários, sendo que nem todos possuem data completa), nível do colaborador (classificação do site para os usuários que comentam), número de estrelas (classificação utilizada para o atrativo quanto a significância) e via app do celular (comentário realizado no aplicativo do celular).

\section{Reputação online: análise dos turistas sobre o parque urbano Lagoa da Jansen}

A Lagoa da Jansen possui uma extensão de 150hectares, com profundidade média de 3,5 metros, localizada no município de São Luís (capital do estado do Maranhão) na área noroeste da ilha, sendo delimitada ao norte com a praia da Ponta D'areia e bairro da Ponta do Farol, ao sul com o bairro do São Francisco, a oeste com o bairro da Ponta D'areia e a leste com os bairros do Renascença I e II (Figura 1) (COELHO, 2002).

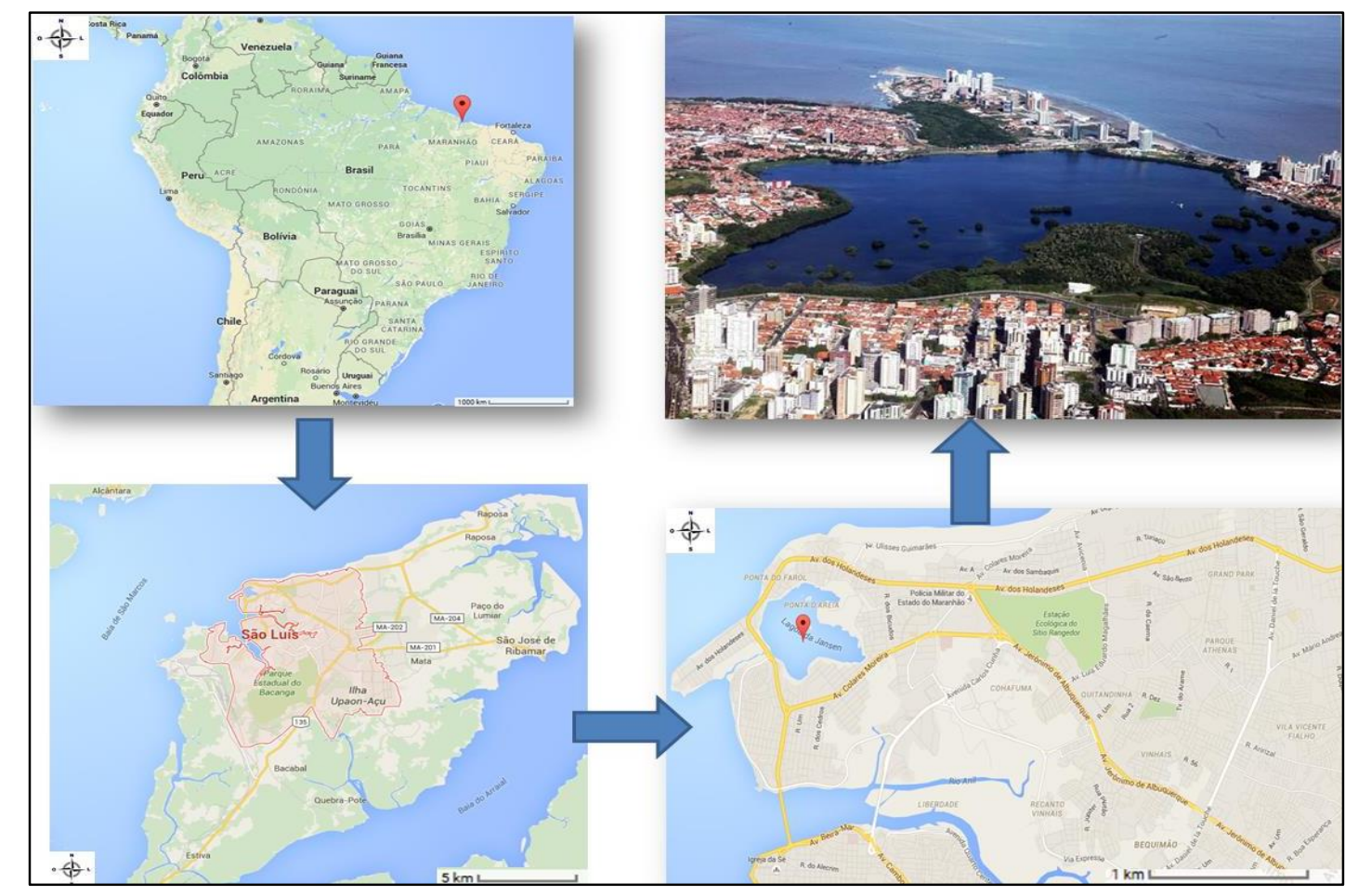

Figura 1: Mapa de localização da Lagoa da Jansen no Brasil e em São Luís Fonte: Adaptado de Google Maps (2016) e Soares (2012).

São Luís vivenciou na década de 70 , a implantação de um complexo siderúrgico com o objetivo de escoar o minério da Serra dos Carajás (Pará) pelo porto, o que gerou a criação de loteamentos com fins habitacionais em diversos locais da cidade, gerando ocupação desenfreada (migração de pessoas do interior e estados vizinhos em busca de emprego) em áreas de mangues e alagadiças, criando uma desordem na estrutura urbana de São Luís (COELHO, 2002). Em 1974, o Plano de Urbanização da Ponta D'areia foi elaborado com o objetivo de transformar o local em um polo turístico e residencial de classe alta, pela proximidade com a praia e o centro da cidade. A Lagoa da Jansen por estar na área do entorno da Ponta D'areia sofreu REINA, Belo Horizonte - MG, Brasil, v.24, n.2, p.89-107, Abr. - Jun. 2019 - ISSN 2179-8834 
diversas invasões e investimentos imobiliários formando um contraste na paisagem (COELHO, 2002).

Na década de 1970, o aterramento para a ligação dos bairros São Francisco e Ponta D’Areia destruiu o igarapé da Jansen, facilitando, assim, o acesso às praias. Deste aterramento, formou-se a Laguna da Jansen, que, em 2001, recebeu obras de infra-estrutura para o lazer e turismo [...]. Com recursos do Ministério do Meio Ambiente, o Governo do Maranhão realizou melhorias na Laguna, principalmente voltadas à despoluição e ao agenciamento de calçadão pontuado por equipamentos esportivos e de lazer (SANTOS et al., 2013, p. 05).

De acordo com a Lei 4.870 de 23 de junho de 1988, a Lagoa da Jansen foi transformada em parque ecológico mediante seu valor estético e paisagístico, além da fauna e flora. Mesmo com a proteção legal, a área continuou sendo foco de especulação imobiliária e invasões acarretando problemas ambientais à localidade (Santos et al., 2013). "Assim, desde a sua construção, o parque foi tido como um local turístico referenciado pela sua beleza ambiental, a pesca artesanal e lazer" (MASULLO et al., 2014, p. 01).

Dentre os 42 comentários pesquisados (TRIPADVISOR, 2016), descartou-se 4, por serem de origem local, ou seja, da cidade de São Luís, sendo que a pesquisa delimitou-se em compreender a visão dos turistas e não dos moradores. Portanto, para análise considerou-se somente 38 comentários. Sobre cada um, estudou-se as características mencionadas no item procedimentos metodológicos, para aproveitamento da valoração e reputação online destes usuários quanto a Lagoa da Jansen.

Conforme María-Dolores, García e Mellinas (2012) qualquer turista pode escrever sobre um serviço, produto e sua experiência e é fundamental destacar as opiniões, pois, são relevantes, além do nível de veracidade destas.

Quanto ao perfil destes, $52 \%$ não responderam a origem/procedência, seguidos de $10 \%$ de Brasília, $8 \%$ da Bahia, $5 \%$ do Ceará e variando entre $2 \%$ e $3 \%$ de outros estados da federação. Dados da Secretaria Municipal de Turismo de São Luís (SÃO LUÍS, 2014) apresentam que 4,64\% dos turistas são provenientes de Brasília, 2,82\% da Bahia e 6,45\% do Ceará, percebe-se semelhança entre os turistas que comentam e os que visitaram a cidade.

Quanto ao sexo, 61\% são do sexo masculino e 39\% feminino, sendo o mesmo resultado da pesquisa da Secretaria Municipal de Turismo de São Luís realizada em 2015, no período junino (SÃO LUÍS, 2014).

O mês de maior número de comentários foi janeiro, com $52 \%$, seguido de dezembro com $46 \%$, e fevereiro com $2 \%$. Justifica-se a concentração dos meses com maiores comentários, justamente os períodos de alta temporada definidos pela Secretaria Municipal de Turismo de São Luís e também são nestes meses que acontecem as pesquisas de demanda (SÃO LUís, 2014).

Com relação ao título que os usuários destacaram nos comentários, boa parte deles foram negativos, enfatizando principalmente o aspecto da poluição e sujeira 
encontrados no local. Estes são alguns exemplos: "Poluída e perigosa"; "Lagoa abandonada"; "Lixo"; "Lagoa aos pedaços"; "Péssimo"; "Sujeira a céu aberto", entre outros.

Títulos como estes remetem a imagem que os usuários possuem sobre o produto visitado, e o conteúdo gerado contribui na avaliação do desempenho do atrativo turístico, pois, de acordo com Quiroga, Mondo e Castro Júnior (2014, p. 98 99):

A internet representa hoje uma das principais ferramentas de pesquisa de mercado que os consumidores utilizam. Dentro do contexto turístico, por ser um serviço, os aspectos tangíveis (fotos, indicação de estruturas e outros) são ponto fundamental na análise e escolha do que consumir. Outro ponto relevante, com grande aceitação no mercado, foram os depoimentos (positivos e negativos) que turistas inserem na internet sobre sua experiência em determinada viagem ou hotel.

A Lagoa da Jansen é um local utilizado pelos autóctones para a prática de esporte e lazer, por outro lado, a poluição e descaso com o ambiente é notório por diversas pessoas que ali transitam. "Trata-se de uma área protegida estadual cujos objetivos originais relacionam-se ao "uso público, diversões, esportes e áreas verdes dentro dos limites a serem fixados pelo Poder Público” (MARANHÃO, 2012).

A maior concentração de infraestrutura urbana no entorno da Laguna da Jansen encontra-se em área correspondente aos bairros Renascença II e Ponta do Farol, com equipamentos para lazer, bares, restaurantes, quadras de tênis, pista de skate, quiosques, pista de ciclismo, concha acústica e mirante. (SANTOS et al., 2013, p. 06).

Em reportagem publicada pelo portal Imirante (2014, s/n), enfatiza o aspecto da poluição como um causador de mau cheiro e reclamações dos frequentadores do parque estadual.

O acúmulo e sedimentos e de restos de matéria orgânica às margens da Lagoa da Jansen, em São Luís, está sendo responsável por um intenso mau cheiro no local. As pessoas que transitam pela área reclamam do odor proveniente da água contaminada, que se intensifica ainda mais por causa da falta de tratamento adequado para os dejetos.

Estes problemas mencionados nos comentários são visíveis também pela população como destacado acima. Ou seja, aspectos de infraestrutura sanitária prejudicam a fauna e a flora, além da paisagem natural do parque ecológico, o que compromete o turismo na região. Mas por outro lado, Santos et al. (2013, p. 08) afirmam que "fica claro, portanto, que um atrativo paisagístico natural, como no caso da laguna, se bem planejado e organizado, pode promover melhorias para determinado setor urbanístico" e turístico, que Sakata (2011, p. 32) corrobora, esclarecendo que: 
A paisagem da lagoa não era valorizada tanto que os empreendimentos construídos antes da obra de urbanização voltaram suas janelas nobres para o mar [...]. Após a implantação do projeto Lagoa da Jansen, as vistas para a lagoa [...] passaram a ser consideradas vistas privilegiadas.

Ou seja, a paisagem natural da laguna da Jansen não é um atrativo somente turístico, mas imobiliário que contribui para a expansão urbana no território do entorno da mesma. Pesquisa de Santos et al. (2013, p. 08) destaca que:

Gradativamente, a paisagem urbana vai se modificando [...] com a urbanização da laguna. Os moradores perceberam aspectos positivos das melhorias estruturais realizadas na região, bem como suas consequências favoráveis [...]. A [Figura 1] evidencia que não só o bairro do Renascença II, mas, de maneira geral, todos os situados nas proximidades da laguna sofreram alterações na paisagem urbana. Ou seja, as intervenções urbanísticas constituíram - e ainda constituem - fatores que impulsionam a transformação paisagística [e turística] do local.

Na figura 2 é possível perceber a verticalização no entorno da laguna, mediante especulação imobiliária, assim como, adensamento de construções com fins de moradia e comercial, criando um espaço de entretenimento e lazer para residentes e visitantes.

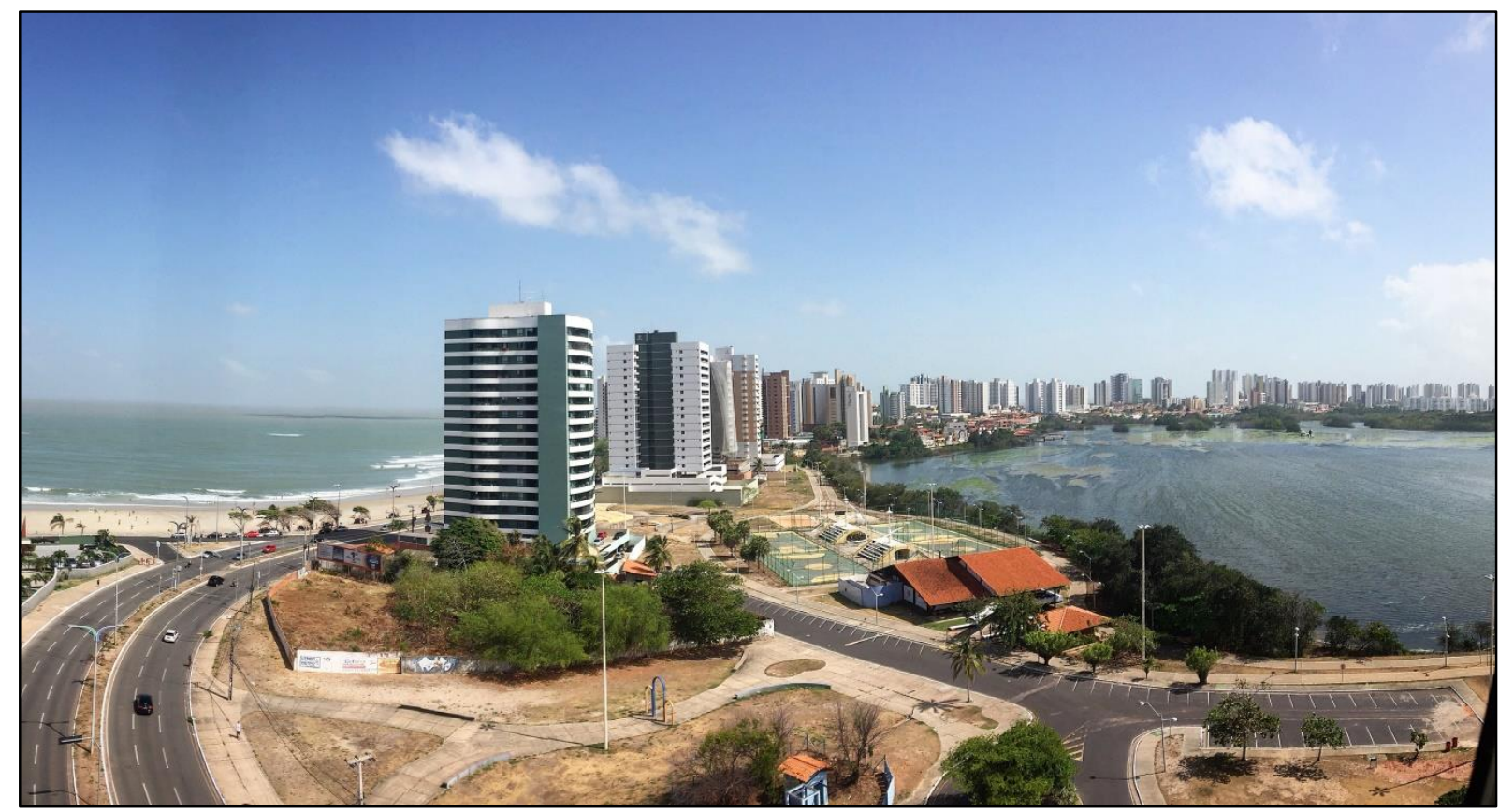

Figura 2: Verticalização no entorno da Laguna da Jansen em São Luís Fonte: Santos (2016). 
Outro item foi o abandono, que de acordo com Odilon Teixeira, professor da Universidade Federal do Maranhão, afirmou que o estado atual em que se encontra o parque ecológico Lagoa da Jansen, é de destruição e insegurança para a população (TEIXEIRA, 2016).

Quebraram tudo, roubaram o que havia lá dentro. Alguns até chegam a brigar por aqui por perto. 'O movimento caiu e a maioria dos turistas que passa por aqui reclama desse abandono', afirmou o vendedor Raimundo Lima Soares, que paga $\mathrm{R} \$ 60$ por mês para ter o direito de utilizar um quiosque bem próximo ao antigo posto (G1 MA, 2012, s/n).

Com o objetivo de reforçar a segurança pública da região da Lagoa da Jansen, em dezembro de 2015, o atual governador do estado do Maranhão, Flávio Dino, entregou à cidade de São Luís "o novo prédio da Companhia de Polícia de Turismo Independente (CPTur), na Lagoa da Jansen. O equipamento fortalece as ações de segurança para moradores e turistas da região da Ponta do Farol, Ilhinha, Ponta d'Areia e São Francisco" (MARANHÃO, 2015, s/n).

[...] 'Contamos com um contingente de 175 oficiais que se revezam entre os plantões e realizam policiamento ostensivo. Os grupos de oficiais fazem rondas a pé e em patrulhas motorizadas que contam com viaturas, motos e quadrículos', informou José Roberto Moreira. Ele ressaltou que os oficiais tem o domínio de mais de um idioma, o que permite orientar grupos de estrangeiros que visitam os locais, transmitindo segurança e cordialidade. [...] Para o comandante da CPTur, tenente-coronel José Roberto Moreira, [...] 'Nós somos aliados da população. O policial precisa deixar de ser visto como aquele indivíduo que só serve para momentos de nervosismo e passar a ser 0 colaborador da paz, ser visto como ser humano que entende e ajuda os cidadãos. Nosso papel é proteger e colaborar para que muitos turistas queiram retornar a nossa cidade', comentou (OITAQUI, 2016, s/p).

O investimento em policiamento tem promovido melhorias na segurança do local, criando um ambiente mais agradável aos turistas que visitam a laguna da Jansen, conforme destacado. A segurança é um dos principais quesitos avaliados por turistas no momento na escolha de um destino turístico, pois, na concepção de Kurež e Prevolšek (2015) a segurança impacta diretamente nos mais diversos segmentos relacionados direta e indiretamente a atividade turística, e este efeito pode ser grande ou pequeno, de acordo com a dependência turística que o destino possui.

Mas também houveram menções positivas como: "Agradável"; "Lindo local”; Recomendo"; "Paisagem bonita"; que remetem a boa imagem que a paisagem natural contrasta com a urbe. E outros, destacaram a vida noturna e gastronômica do local, com títulos como: "'Vá a noite"; "Agitado"; "Ótimo bares"; "Bares"; "Badalação maranhense".

O conteúdo gerado pelo consumidor ou usuário (consumer/user generated content - CGC - UGC), principalmente, ao que se refere à produção, armazenamento e distribuição de informação 
e opiniões sobre produtos e serviços consumidos vem crescendo, devido ao aumento do alcance da Web dentro da sociedade, especialmente, quando se aborda a utilização de mídias sociais, que tem como um dos intuitos divulgar a opinião dos usuários frente ao que está sendo ofertado no mercado (QUIROGA; MONDO; CASTRO JÚNIOR, 2014, p. 99).

Quanto a análise dos comentários, dividiu-se entre positivos e negativos, cabendo destacar que alguns enfatizam tanto aspectos positivos quanto negativos:

a) Positivos:

A vista da Lagoa do Jansen é bem interessante, consegue-se ver algumas embarcações trafegando na lagoa.

Bom lugar com bares e casas noturnas. Com boas opções de restaurantes. Ambiente relativamente seguro durante a noite é próximo a diversos hotéis.

Bom o local precisa de algumas melhorias, porem é um lugar bonito, mas precisa ser restaurado muitas coisas.

Este ambiente é de muita beleza natural. O demérito está na estrutura construída: feia, sem um conceito arquitetônico.

Possui bares e restaurantes excelentes durante a noite boates aluguel de patins e charrete

Tive o prazer de me hospedar em frente dessa área de preservação ambiental. Possui duas pistas, uma para bicicletas e outras para corrida/caminhada com extensão de $5 \mathrm{~km}$. Ainda tem barracas de água de coco em alguns locais.

Lagoa apresenta um traço marcante na paisagem de São Luís. Ao lado do mar e dos rios que cortam a cidade dá um tom especial a geografia da cidade. Apesar de sofrer com a disposição de esgoto, comum na maioria dos corpos d'água das cidades brasileiras, mesmo assim é um lugar bonito para se contemplar.

A grande concentração de bares e restaurantes tornam a região um prato cheio pros que gostam de uma noite agitada. Tem opções pra todos os gostos.

São destacados a paisagem natural, o entretenimento e a vida gastronômica do local. Pois, por tratar-se de um local turístico de São Luís, concentra diversos empreendimentos que ofertam serviços no segmento da alimentação e lazer como bares e restaurantes. 
A Lagoa da Jansen se encontra em uma região urbanizada, totalmente habitada em seu perímetro marginal, rodeada por pavimentação de calçadas, ciclovias e estradas asfaltadas. Em seu entorno encontram-se moradias em forma de casa e edifícios, além de prédios comerciais, bares e restaurantes (MARANHÃO, 2012, p. 07).

Em pesquisa realizada por Santos et al. (2013, p. 10) com moradores de um dos bairros que circundam a laguna, evidenciaram também aspectos quanto ao lazer e entretenimento na região.
A grande maioria dos entrevistados afirmou que a paisagem urbana $(31 \%)$ e as opções de entretenimento $(31 \%)$ foram os itens que mais mudaram no bairro. Ou seja, é visível que os componentes paisagísticos do Renascença II foram rapidamente influenciados pelas medidas de agenciamento urbano da laguna [...]. Outras alternativas de lazer (12\%) aparecem em terceiro lugar, devido também à oferta de equipamentos para essa finalidade na região da laguna, principalmente na parte do Renascença II, como pista de skate, equipamentos de musculação, concha acústica e praça.

Da relação da paisagem com o turismo, entende-se que este é um vetor de desenvolvimento da atividade (SANTOS, 2015), pois, trata de um atrativo que o turista muitas vezes busca, seja no âmbito natural ou urbano, além de ser diretamente influenciada pelas ações antrópicas no decorrer das incorporações estratégicas promovidas pelas políticas públicas (SANTOS et al., 2013).

Na visão de Yázigi (2002), a paisagem é objeto de interesse dos moradores, mas também dos turistas por possuir significados, símbolos, que estimula e desperta a atenção "pela diferença do cotidiano ao qual pertencem, desempenhando várias funções: espaço mediador da vida em sociedade, referencial (geográfica, psicológica, entre outras), fonte de contemplação e inspiração, etc." (DAL MOLIN; OLIVEIRA, 2008, p. 08).

No documento oficial do turismo maranhense (Plano Maior 2020) a laguna da Jansen está classificada como um recurso de alta prioridade, que são aqueles que possuem valores potenciais elevados e que precisam de alguns investimentos em desenvolvimento e comunicação e que podem gerar receitas por meio da atividade turística, quando devidamente organizados, contribuindo desta forma, com a consolidação da imagem e posicionamento do Maranhão no mercado turístico (MARANHÃO, 2012).

\section{b) Negativos:}

A Lagoa é poluída, com pouquíssimas pessoas caminhando, clima de insegurança e nada interessante para fazer.

Não só a lagoa, mas a maioria dos pontos turísticos de São Luís estão largados. Sem conservação, esperava um local agradável com locais para sentar e relaxar. Quem percorre o perímetro da lagoa encontra até porcos soltos. Decepção. 
$\mathrm{Na}$ internet vi que a lagoa de Jansen era um lugar turístico, dessa forma resolvi ir até o local ver. A visita foi frustrante, pois é uma lagoa que tinha tudo para ser um dos melhores lugares da cidade, mas ao invés disso acumula muito sujeira, lodo, brinquedos abandonados da mesma forma que a lagoa cheia de esgoto abandonada. O que salva são o restaurantes e bares das imediações da lagoa.

Atualmente eles estão despoluindo e revitalizando a lagoa, pois o cheiro e a poluição estava insuportável. Sei que vai levar um tempo para fazerem isso tudo e também tirarem o esgoto que nela desagua. Muito linda mas não limpa!!!

Esse lugar poderia ter sido melhor conservado pela população, caso fosse, seria muito bonito. O local tem lixo e está totalmente contaminado, seco, sujo e abandonado. Na orla tem um calçadão e as pessoas fazem caminhadas e corridas. $\mathrm{Na}$ paisagem deixa a desejar...

Um lugar muito bonito, mas infelizmente esta maltratada. As quadras de esporte estão todas depredadas e caminhar ali já se torna perigoso...

A Lagoa em si é péssima! Fedorenta e perigosa. Ao lado dela tem vários bares legais, por ficarem do lado contrário ao que o vento sopra o fedor não chega na maioria deles.

A vista é bem bonita, mas tu não consegues ficar muito tempo por causa da catinga. É altamente poluída, fede muito. No outro lado da lagoa está a vida noturna de São Luís. Muitos bares legais.

Apesar do bairro ser bom, com prédios de alto nível, a lagoa está exalando um cheiro muito ruim e as calçadas de seu perímetro estão mal conservadas.

Ratificando os aspectos negativos, Masullo et al. (2014, p. 5) afirmam que:

A área sofre, ainda, uma série de impactos ambientais, destacando-se os processos de eutrofização e colmatagem. Os esgotos são lançados in natura e acabam por contribuir para a multiplicação de algas cianofíceas que sufocam e matam o zooplâncton e os animais de maior porte cuja decomposição libera gases fétidos em grande intensidade.

Com a urbanização da Lagoa, o local foi favorecido com espaços para a prática de lazer e esporte por moradores e turistas, transformando-se numa referência, por representar a identidade local e também, onde estão inseridas as memórias sociais e a história da cidade. 
O processo de urbanização que se procede na Laguna da Jansen é um dos graves problemas ambientais que ocorrem na região, impulsionados pela ocupação desordenada de sua orla e adjacências. Essa crescente demanda de construções, onde se destacam vários prédios de grande porte que despejam uma grande quantidade de esgotos domésticos nos corpos d'água e os resíduos sólidos jogados as suas margens, deixando a laguna em progressivo estado de eutrofização, bem como gerando diversos outros impactos subsequentes (MASULLO et al., 2014, p. 4).

Portanto, preservar e conservar o ambiente natural são fundamentais para que a satisfação dos frequentadores e turistas seja positiva, pois, isso reflete na imagem do destino turístico (GÂNDARA, 2008; MARUJO, 2008) e também nos comentários que podem ser gerados em sites especializados de turismo como o Tripadvisor (BEAL; STRAUSS, 2008).

Políticas públicas a nível estadual estão sendo realizadas quanto à balneabilidade das praias e despoluição de rios urbanos e da lagoa, que irão favorecer diretamente na qualidade de vida da população e turismo.

Serão investidos mais de $R \$ 14$ milhões nas obras de saneamento nesta etapa do 'Mais Saneamento'. Ao priorizar a meta de elevar o nível de tratamento de esgoto de São Luís, de 4\% para $70 \%$ até o final de 2018, o Governo do Estado garante qualidade de vida, proteção ao meio ambiente e incentivo ao turismo no Maranhão (MARANHÃO, 2016, s/p).

Ações do atual governo do estado do Maranhão por intermédio da Companhia de Saneamento Ambiental do Maranhão (CAEMA) quanto à despoluição, promete retirar 27 pontos de lançamento de esgoto.

Com estas ações conjuntas, em poucos meses nós vamos garantir condições bem melhores do ponto de vista de qualidade da água da Lagoa, viabilizando, assim, atividades que não são hoje praticadas, como esportes náuticos, e incrementando, também, ente outras coisas, o turismo nesta área (MARANHÃO, 2016, s/p).

Informações sobre a despoluição da laguna publicada no site oficial do governo do Maranhão em dezembro de 2016, esclarecem que:

[...] dentro de alguns meses, será possível apreciar, na Lagoa e nas ruas que a circundam, mudanças resultantes deste trabalho que já interfere positivamente na vida dos moradores do entorno. Além da retirada de pontos de lançamento de esgotos clandestinos das margens da Lagoa - destinando-os para a 
elevatória instalada no local e a partir dela, enviando e tratando efluentes na ETE Jaracati - há, também, o projeto de organização e implantação de redes em curso (MARANHÃO, 2016, s/p).

Seguindo a metodologia de Quiroga, Mondo e Castro Júnior (2014), quanto ao nível do colaborador, o TripAdvisor classifica-os entre 1 e 6 . Quanto maior a numeração, maior é valor que este usuário possui em relação ao número de postagens e contribuições realizadas no site. Portanto, os usuários de classificação 3 tiveram o maior número de comentários (32\%), seguidos do de classificação 5 com $29 \%$ e $14 \%$ os usuários classificados com nível 4.

Os colaboradores de nível 3, 5 e 4 foram os que mais comentaram e, portanto, torna-se confiável a opinião destes para o leitor, pois, esta classificação do TripAdvisor para o comentarista representa confiabilidade para o leitor. $E$ a internet, tem sido utilizada como um meio para obter informações sobre o destino (IVARS BAIDAL et al., 2014), e em São Luís, cerca de 0,20\% apontaram que a internet foi um veículo que influenciou na escolha da mesma como opção, frente a outros destinos consolidados (SÃO LUÍS, 2014).

O viajante de hoje tem um apetite voraz por todo e qualquer tipo de informação tradicional e online, com o objetivo de planejar sua viagem antes e durante. $O$ aumento do uso da informação virtual é também um fenômeno que transcende os viajantes de todas as idades e níveis de afluência (BROWN, 2015, p. 23, tradução nossa).

Em relação à classificação do atrativo Lagoa da Jansen sob a ótica dos usuários, a maioria (31\%) opinou como 3 estrelas, seguidos de 2 estrelas com $29 \%$ e $21 \%$ com 4 estrelas. No documento oficial do turismo do estado do Maranhão, Plano Maior, a Lagoa da Jansen está classificada como recurso de alta prioridade no polo turístico São Luís, o que equivale ao conceito de 4 e 5 estrelas.

Os Recursos de Alta Prioridade para o desenvolvimento são, portanto, os que possuem valores potenciais mais elevados, podendo constituir-se futuramente em produtos $A$ ou $B$ por meio de ações estruturantes. Necessitam de consideráveis investimentos em desenvolvimento e comunicação, mas poderão gerar receitas importantes por meio do turismo quando devidamente organizados, e contribuir na consolidação da imagem e do posicionamento do Estado no mercado turístico (MARANHÃO, 2012, p. 104).

Quanto àqueles que avaliaram o atrativo pelo aplicativo do TripAdvisor para celular, foram $50 \%$, assim como pelo site da organização. Já se percebe a importância deste instrumento, bem como o fato dos turistas postarem seus comentários no mesmo momento em que vivem as experiências (BLANCO, 2015; SEGITTUR, 2013; 2015). 
O avanço da tecnologia no turismo tem proporcionado maior conectividade aos turistas, impulsionados pela inovação (HJALAGER, 2000), abrindo oportunidades diversas para o setor. A capacidade de processamento de dados é alta, criando produtos e valores que integram todos que estão ligados direta e indiretamente com o turismo (BLANCO, 2015).

As ferramentas tecnológicas como o TripAdvisor possuem a capacidade de conectar e ampliar a comunicação entre os usuários. Portanto, no turismo está cada vez mais afetada por esta mudança, configurando uma nova forma da atividade (BLANCO, 2015).

Esclarece-se que a reputação online, tem crescido nos últimos anos e o monitoramento de mídias sociais é uma ferramenta de pesquisa para compreender as métricas válidas, a fim de compreender e analisar informações e dados postados para então desenvolver políticas públicas e planos de turismo (SANTOS et al., 2016).

\section{Considerações finais}

Compreende-se que o avanço da tecnologia tem favorecido o surgimento de novas ferramentas que contribuem para a propagação de informações acerca dos destinos turísticos, ampliando o contato entre os turistas e visitantes, assim como moradores, como o caso de diversos sites de turismo, em específico o analisando, TripAdvisor, que tornou-se uma referência para viajantes em busca de dicas e sugestões de passeios, hospedagem, restaurantes, bares, entre outros.

Viu-se que a reputação online é responsável na decisão da escolha (decisão) ou não de um destino turístico, portanto, manter-se competitivo no mercado turístico, requer do destino ampliar a qualidade e a experiência para o visitante. Além disso, é o conjunto de opiniões dos consumidores que se realiza na internet sobre o produto, serviço e marca, portanto, este torna-se um certificador, pois, estes atribuem veracidade e confiança sobre os comentários postados, além de promovem a divulgação e comunicação do atrativo na internet.

Quanto ao parque estadual da Lagoa da Jansen, analisou-se os comentários, identificando tanto os positivos, quanto negativos. Por tratar-se de um atrativo turístico da cidade de São Luís, e mediante os users, há um destaque a questão da poluição e insegurança do local, que de certo modo cria uma imagem negativa a mesma.

Portanto, políticas públicas tanto ambientais quanto turísticas devem promover a valorização deste território criando possibilidades de melhoria sanitária, conforme o governo do estado vem desenvolvendo com fins de devolver a população e turistas um local agradável para a prática de esportes e lazer.

Por outro lado, identificou-se comentários positivos que ratificaram o valor paisagístico do local, que é um dos principais produtos que o turismo utiliza na comercialização de um destino. Percebe-se neste sentido, que os comentários contribuem para que se entenda o território, contribuindo para que o turista obtenha cada vez mais informações acerca do atrativo e tenha experiência positiva.

Como forma de ampliar pesquisas científicas em torno do destino turístico São Luís, e aprofundar sobre a metodologia de reputação online (comentários), sugere-se que novas pesquisas sejam realizadas tratando dos aspectos da impressão dos 
visitantes após a leitura dos comentários no site Tripadvisor no destino São Luís, relacionadas a outros atrativos da cidade.

\section{Referências}

BAGGIO, R.; DEL CHIAPPA, G. Real and virtual relationships in tourism digital ecosystems. Information Technology and Tourism, v. 14, n. 1, p. 319, 2014.

BARICH, H.; KOTLER, P. A framework for marketing image management. Sloan Management Review, v. 32, n. 2, 1991, p. 94-104.

BEAL, A. ; STRAUSS, J. Radically transparent: monitoring and managing reputations online. Sybex: Wiley, 2008.

BLANCO, F. J. Libro blanco de los destinos turísticos inteligentes. Madrid: Acción Empresarial de LID Editorial, 2015.

BUHALIS, D. Tourism and information technologies: Past, Present and Future. Tourism Recreation Research. v. 25, n. 1, 2000, p. 41-58.

BROWN, Millward. Visa global travel intentions study 2015. Executive Summary. 2015.

CERQUEIRA, R. ; SILVA, T. Mensuração em mídias sociais: quarto âmbitos de métricas. In: CHAMUSCA, M. e CARVALHAL, M. 2011. Comunicação e marketing digitais: conceitos, práticas, métricas e inovações. Salvador: VNI. Disponível em: < http://www.slideshare.net/tarushijio/comunicacao-e-marketing-digitais-conceitospraticas-metricas-e-inovacoes. Acesso em: 26 jan. 2016.

CERVO, A. L.; BERVIAN, P. A. Metodologia científica. São Paulo: Pearson Pratice Hall, 2004.

CHUN, R. Corporate reputation: meaning and measurement. International Journal of Management Reviews, v. V, 2005, p. 91-109.

COELHO, M. T. de M. Avaliação da eficácia da lei de uso e ocupação do solo em São Luis: o caso da Lagoa da Jansen. 145f. Dissertação. (Mestrado em Desenvolvimento Urbano) - Universidade Federal de Pernambuco, Recife, PE, 2002.

CRESWELL, J. W. Projeto de pesquisa: métodos qualitativo, quantitativo e misto. Porto Alegre: Artmed, 2007.

DAL MOLIN, Elisiane Dondé; OLIVEIRA, Josildete Pereira de. Paisagem urbana e uso turístico: revitalização da rua Hercílio Luz em Itajaí (SC). Revista Eletrônica de Turismo Cultural. v. 02, n. 01, 2008, p. 01-22.

GÂNDARA, J. M. G. A imagem dos destinos turísticos urbanos. Revista Eletrônica de Turismo Cultural. Número Especial, 2008, 1-22. 
GÂNDARA, J. M. G. ; FRAIZ BREA, J. A. ; MANOSSO, F. Calidad de la experiencia en los hoteles termales de Galicia, Espana: un analisis a traves de la reputacion on line. Estudios y Perspectivas en Turismo (En Línea), v. 22, 2013, p. 492-525.

GIL, A. C. Como elaborar projetos de pesquisa. São Paulo: Atlas, 2006.

GOOGLE MAPS. Localização da lagoa da jansen. Disponível em: < https://www.google.com.br/maps/place/Parque+Estadual+da+Lagoa+da+Jansen/@2.4960898,-

44.2971476,17z/data=!3m1!4b1!4m5!3m4!1s0x7f68c30e738ca29:0x1d1493aea1ea2 2ea!8m2!3d-2.4960898!4d-44.2949589>. Acesso em: 14 dez. 2016.

G1 MARANHÃO. Lagoa da Jansen apresenta problemas de infraestrutura. 2012. Disponível em: <http://g1.globo.com/ma/maranhao/noticia/2012/05/lagoa-da-jansenapresenta-problemas-de-infraestrutura.html>. Acesso em: 16 abr. 2016.

HJALAGER, Anne-Mette. Tourism destinations and the concept of industrial districts. Tourism and Hospitality Research, v. 2, n. 3, p. 199-213, 2000.

IMIRANTE. Lixo na Lagoa da Jansen provoca mau cheiro e causa reclamações. 2014. Disponível em: <http://imirante.com/sao-luis/noticias/2014/04/15/lixo-na-lagoada-jansen-provoca-mau-cheiro-e-causa-reclamacoes.shtml>. Acesso em: $16 \mathrm{abr}$. 2016.

IVARS BAIDAL, J. A; RODRÍGUEZ SÁNCHEZ, I.; VERA REBOLLO, J. F.; ACEBAL, A. Nuevos enfoques em gestión turística: el programa de agrupaciones empresariales inovadoras em España. Boletín de la Asociación de Geógrafos Españoles. n. 66, p. 369-395, 2014.

KUREŽ, Bojan; PREVOLŠEK, Boris. Influence of security threats on tourism destination development. Fakultet za sport i turizam, Novi Sad, TIMS, n. 9, 2015, p. 159-168.

LAW, R. ; QI, S.; BUHALIS, D. Progress in tourism management: a review of website evaluation in tourism research. Tourism Management. v. 31, n. 3, jun., 2010, p. 297313.

LIU, Z. Internet tourism marketing: potential and constraints. Fourth International Conference Tourism in Southeast Asia \& Indo-China: Development, Marketing and Sustainability. The Scottish Hotel School. University of Strathclyde, UK, 2000.

MARANHÃO. Governo do Estado. 2015. Mais segurança para moradores e turistas na Lagoa da Jansen. Disponível em: <http://www.ma.gov.br/mais-seguranca-paramoradores-e-turistas-na-lagoa-da-jansen/>. Acesso em: 15 abr. 2016.

MARANHÃO. Governo do Estado. 2016. Mais segurança para moradores e turistas na Lagoa da Jansen. Disponível em: <http://www.ma.gov.br/retirada-de-pontos-deesgoto-garante-despoluicao-da-lagoa-da-jansen/>. Acesso em: 25 maio 2016.

MARANHÃO. Governo do Estado. Plano estratégico de turismo do estado do Maranhão: plano maior 2020 - Relatório final. São Paulo: Chias Marketing, 2012. 
MARÍA-DOLORES, S. M.; BERNAL GARCÍA, J. J, ; MELLINAS, J. P. Los hoteles de la región de Murcia ante las redes sociales y la reputación online. Revista de Análisis Turístico, v. 13, 2012, p. 1- 10.

MARUJO, M. N. N. V. A internet como novo meio de comunicação para os destinos turísticos: o caso da llha da Madeira. Turismo em Análise. v. 19, n. 1, maio, 2008, p. $25-42$.

MASON, J. C. What image do you project? Management Review, v. 82, n. 11, 1993, p. 10-16.

MASUlLO, Y. A. G.; FERREIRA, A. R. F.; SANTOS, A. F. dos; SOARES, A. B. C.; FERREIRA, A. P. Análise multitemporal do uso e ocupação do solo na Lagoa da Jansen-MA. V. Congresso Brasileiro de Gestão Ambiental. Belo Horizonte, 2014.

MONTARDO, S. Conteúdo gerado pelo consumidor: reflexões sobre sua apropriação pela comunicação corporativa. Revista Brasileira de Ciências da Comunicação. São Paulo, v. 33, n. 2, jul./dez., 2009, p. 161-180.

OITAQUI. Turistas aprovam policiamento realizado pela companhia de turismo independente. 2016. Disponível em: http://www.oitaqui.com.br/cidade/2016/07/19/turistas-aprovam-policiamento-

realizado-pela-companhia-de-turismo-independente.html> . Acesso em: 10 jan. 2017.

PINTO, R. A Formação das imagens no turismo: itinerário teórico e proposta de um modelo operacional. Turismo em Análise. v. 23, n. 3, 2012, p. 552-574.

QUIROGA, R. M.; MONDO, T. S. ; CASTRO JÚNIOR, DEOSIR F. L. de. Reputação online como instrumento para melhoria de serviços: um estudo na hotelaria de Garopaba e Imbituba - Santa Catarina. Revista de Turismo Contemporâneo, v. 2, n. 1, jan./jul., 2014, p. 95-112.

REINO, S. S.; A. LAMSFUS, C.; AZUA-SORZABAL, A. A new hotel online reputation framework for ontology learning development. Helsingborg, Sweden, 2012.

SAKATA, F. G. Paisagismo urbano: requalificação e criação de imagens. São Paulo: Editora da Universidade de São Paulo - EDUSP, 2011.

SANTOS, S. R. dos; HARDT, L. P. A.; HARDT, C.; SANTOS, P. C. dos. (2013). Transformações da paisagem urbana do bairro Renascença II em São Luís (MA) sob a ótica dos moradores. In: MATTOS JÚNIOR, J. S. de; SANTOS, P. C. dos. (Org.) Desenvolvimento socioespacial: novos olhares. São Luís: EDUEMA, 2013, p. 201 220.

SANTOS, S. R. dos. Paisagem solidária: indicadores de sustentabilidade urbana em área turística funcional do centro histórico de São Luís, Maranhão. 582f. Tese. (Doutorado em Gestão Urbana) - Pontifícia Universidade Católica do Paraná, Curitiba, 2015. 
SANTOS, Saulo R. dos; SOUZA NETO, Valério R. de; PEREIRA, Luciano R. S.; GÂNDARA, J. M. G.; SILVA, Saulo R. X. da. Destino turístico inteligente: acessibilidade no centro histórico de São Luís - Maranhão, um estudo sobre a reputação online no TripAdvisor. Marketing \& Tourism Review. v.1, n. 2, 2016, p. 127.

SANTOS, S. R. dos. Imagem da lagoa da jansen em São Luís. 2016.

SÃO LUÍS. Secretaria Municipal de Turismo de São Luís. Pesquisa de turismo receptivo / festa junina: relatório. São Luís, junho, 2014.

SEGITTUR. Destinos turísticos inteligentes. 2013. Disponível em: $<$ http://www.segittur.es/opencms/export/sites/segitur/.content/galerias/descarga s/doc umentos/Presentacin-Destinos-Tursticos-Inteligentes.pdf >. Acesso em: 23 set. 2016.

SEGITTUR. Smart destination: informe destinos turísticos inteligentes: construyendo el futuro. Madrid. 2015.

SOARES, Z. Maranhão realiza virada pela sustentabilidade. 2012. Disponível em: <http://www.blogsoestado.com/zecasoares/2012/12/14/maranhao-realiza-viradapela-sustentabilidade/>. Acesso em: 25 jan. 2016.

SOLOMON, M. O comportamento do consumidor: comprando, possuindo e sendo. Porto Alegre: Bookman, 2011.

STEINKE, V. A.; REIS JUNIOR, D. F.; COSTA, E. B. (orgs.). Geografia e fotografia: apontamentos teóricos e metodológicos. Brasília: LAGIM-UNB, 2014.

TEIXEIRA, O. Entrevista concedida no portal SuaCidade.com - Lagoa da Jansen sofre os efeitos do abandono. 2016. Disponível em: <http://www.suacidade.com/20121219/lagoa-da-jansen-sofre-os-efeitos-doabandono >. Acesso em: 15 abr. 2016.

TRIPADVISOR. Lagoa da Jansen. 2013. Disponível em: < https://www.tripadvisor.com.br/Attraction_Review-g673267-d2391623-ReviewsLagoa_da_Jansen-Sao_Luis_State_of_Maranhao.html>. Acesso em: 20 jan. 2016.

YÁZIGI, E. Turismo e paisagem. São Paulo: Contexto, 2002. 